\title{
Prediction of Corrosion-Induced Crack Width of Corroded Reinforced Concrete Structures
}

\author{
Jin Xia and Wei-Liang Jin \\ Institute of Structural Engineering, Zhejiang University
}

\begin{abstract}
This paper presents an experimental investigation on the crack width induced by the corrosion of reinforcing steel bars in concrete. Reinforcing steel bars with different diameters were corroded using an accelerated test in three types of concrete members, including 24 beams with corroded stirrup and 20 beams with corroded longitudinal reinforcing steel bars. The corrosion patterns and rusts characteristics of the corroded steel bars were examined and compared with those observed in real RC structures. According to the experimental result, the corrosioninduced crack width were analyzed and showed a linear relationship with the corrosion loss of reinforcing steel bar. Finally, an analytical prediction model of crack width was established after considering concrete cover depth and corrosion penetration depth.
\end{abstract}

Keywords: structural concrete, crack width, corrosion, reinforcing steel bar, multienvironments

\section{INTRODUCTION}

Corrosion of reinforcing steel in concrete is the main cause of deterioration of reinforced concrete (RC) structures, and it is also an important issue that needs to be considered when evaluating and rehabilitating $\mathrm{RC}$ structures. Random distribution of pore spaces suggests that aggressive substances, such as chloride, carbon dioxide, oxygen, and moisture, may penetrate through the weak points of the concrete cover (Allamt, Maslehuddin, Sariciment, \& Al Mana, 1994), break down the passive, trigger the corrosion of reinforcing steel bars in concrete (Richardson, 2002), induce the cracking of the concrete (Williamson \& Clark, 2000), and finally deteriorate the load-bearing capacity of RC structure.

Often, corrosion of steel rebar is the most important input parameter to study the residual performance of corroded RC structure. To this purpose, researchers have been trying to use nondestructive techniques to obtain the corrosion rate of steel rebar embedded in concrete (Monteiro, Morrison, \& Frangos, 1998). However, these methods cannot provide us precise information about the corrosion-induced steel rebar section loss until now (Song \& Saraswathy, 2007). Visual inspection is an accessible and effective alternative method to evaluate the state of corrosion of in situ corroded structural members (Stewart, 2010). As corrosion-induced crack width is the common visual indicator of corrosion presence, corrosion crack widths have been shown to always effectively increase with the steel corrosion level (Suo \& Stewart, 2009).

Therefore, considerable experiments and models have been devoted to study the relation between corrosion crack widths and corrosion loss of steel rebar. In experimental investigations on corrosion-induced crack width in concrete, most of the corrosion process (Aligizaki, 1999; Alonso, Andrade, Rodriguez, \& Diez, 1998; Andrade, Alonso, \& Molina, 1993; Rodriguez, Ortega, Casal, \& Diez, 1996a; Vu, Stewart, \& Mullard, 2005 ) is accelerated by applying a current, so that the concrete cracking can be achieved in a relatively short time. However, the corrosion process caused by electrically accelerated tests is very different from natural corrosion and generates the link between corrosion crack widths and corrosion level, which may not be representative of the real on site situation. Vidal, Castel, and Francois (2004) and Zhang, Castel, and François (2010) studied three beams corroded in an aggressive saline environment and subjected to wetting-drying cycles and sustained loading for about 14, 17, and 23 years and found the wettingdrying cycle-induced corrosion was very much closer to natural chloride-induced corrosion. Although this method can provide a result much closer to the real on site corrosion, it involves a very time consuming process. Xia, Jin, and Li (2011) and Malumbela, Moyo, and Alexander (2011) proposed a wetting-dryingcurrent experimental program trying to combine the advantages of the above-mentioned two methods and found that the accelerated wetting-drying-current method can also produce a corrosion distribution, corrosion type, and oxides, which were very much closer to those of natural chloride-induced corrosion (Xia, Jin, Zhao, \& Li, 2013).

Moreover, to assess the relation between corrosion crack widths and corrosion level, knowledge of factors controlling crack initiation and propagation is essential. 
Usually, the key factors include cover/diameter ratio, corrosion rate, concrete quality, and corrosion process (Alonso et al., 1998). Unfortunately, most of the previous crack propagation empirical models have been obtained and/or calibrated/validated based on limited experimental data (Vidal et al., 2004; Zhang, 2010). Also, due to the lack of experimental data, quantitative verification of the analytical/numerical model is not possible (Li, Melchers, \& Zheng, 2006). Therefore, this does not provide sufficient information for identifying the most accurate and efficient models and, consequently, creates problems in selecting appropriate models for estimating the corrosion level of a cracked concrete. In this case, further research, in particular experimental, is needed to improve exist crack propagation models or establish new precise models.

This article investigates the crack propagation process by conducting wetting-drying-current accelerated corrosion tests of RC beams and provides new data on crack propagation. A new empirical model for crack propagation is proposed. Besides, a statistical relationship between the maximum crack width and average crack width is proposed. This suggests the possibility of a very much simple mean to evaluate the corrosion level of in situ RC structures.

\section{EXPERIMENTAL INVESTIGATION}

Experiments were conducted, which involved 24 beams with corroded stirrup and 20 beams with corroded longitudinal reinforcing steel bars. The concrete members were corroded using a designed wetting-drying-current acceleration method. The corrosion patterns and rusts characteristics of the corroded steel bars were examined and compared with those observed in real RC structures. The concrete surface crack widths were recorded, and steel rebar section loss were measured after removing the reinforcing steel from the concrete samples.

\subsection{Specimen details and specimen preparation}

Two types of concrete mixes (see Table 1 for the details) were used for the tested reinforced concrete members. In both mixes, ordinary Portland cement with a compressive strength of $42.5 \mathrm{MPa}$ (cylinder specimen test) and coarse aggregate with $16 \mathrm{~mm}$ maximum size gravel were used. The designed slump constant was $70 \mathrm{~mm}$. For each mix, three $150 \mathrm{~mm} \times 150 \mathrm{~mm} \times 150 \mathrm{~mm}$ cubic specimens were casted. The 28-day compressive strength of the casted cubic specimen was about 25.93 MPa for mix I and $35.55 \mathrm{MPa}$ for mix II, respectively.

Figure 1 shows the details of the dimension and reinforcement arranged in the tested specimens. All of the $\mathrm{S} 1$ and $\mathrm{S} 2$ beams tested have the same
Table 1. Concrete mix proportion.

\begin{tabular}{lccccc}
\hline $\begin{array}{l}\text { Concrete } \\
\text { type }\end{array}$ & $\begin{array}{c}\text { w/c } \\
\text { Ratio }\end{array}$ & $\begin{array}{c}\text { Water } \\
\left(\mathbf{k g} / \mathbf{m}^{3}\right)\end{array}$ & $\begin{array}{c}\text { Cement } \\
\left(\mathbf{k g} / \mathbf{m}^{3}\right)\end{array}$ & $\begin{array}{c}\text { Fine } \\
\text { aggregate } \\
\left(\mathbf{k g} / \mathbf{m}^{3}\right)\end{array}$ & $\begin{array}{c}\text { Coarse } \\
\text { aggregate } \\
\left(\mathbf{k g} / \mathbf{m}^{3}\right)\end{array}$ \\
\hline $\mathrm{I}$ & 0.53 & 220 & 412.5 & 641.2 & 1046.1 \\
$\mathrm{II}$ & 0.36 & 220 & 611.6 & 486.4 & 1033.5 \\
\hline
\end{tabular}

dimensions, which are $230 \mathrm{~mm}$ in depth, $120 \mathrm{~mm}$ in width, and $1200 \mathrm{~mm}$ in length. All of the tested beams have the top layer of steel rebar with two $10 \mathrm{~mm}$ rebars, the bottom layer of two $20 \mathrm{~mm}$ flexural steel rebar anchored using a standard hook length of $100 \mathrm{~mm}$ to prevent anchorage failures, a clear concrete cover of $30 \mathrm{~mm}$, and two pieces of $30 \mathrm{~mm} \times 300 \mathrm{~mm} \times 0.2 \mathrm{~mm}$ stainless steel sheets located in the middle layer of the shear zones near the beam ends. S1 beams were arranged using $100 \mathrm{~mm}$ stirrup spacing with a diameter of $6 \mathrm{~mm}$ and $\mathrm{S} 2$ beams were arranged using $150 \mathrm{~mm}$ stirrup spacing with a diameter of $8 \mathrm{~mm}$. S1 and S2 beams were cast using concrete type I. All of the F1 and F2 beams tested have the same dimensions, which are $200 \mathrm{~mm}$ in depth, $150 \mathrm{~mm}$ in width, and $1500 \mathrm{~mm}$ in length. All of the tested beams have the top layer of steel rebar with two $10 \mathrm{~mm}$ rebars, the bottom layer of two $16 \mathrm{~mm}$ flexural steel rebars anchored using a standard hook length of $100 \mathrm{~mm}$ to prevent anchorage failures, a clear concrete cover of $30 \mathrm{~mm}$, and a piece of $30 \mathrm{~mm} \times 1300 \mathrm{~mm} \times 0.2 \mathrm{~mm}$ stainless steel sheet in the middle layer of the beams, $100 \mathrm{~mm}$ stirrup spacing with a diameter of 8 and $10 \mathrm{~mm}$ were used for $\mathrm{F} 1$ and $F 2$, respectively. F1 and F2 beams were cast using concrete type I and type II, respectively. The stainless steel sheet was used to be acting as an anode for the electromigration test, which will be described in the next section. Details of the specimen setup can be found in Xia et al. (2011, 2012).
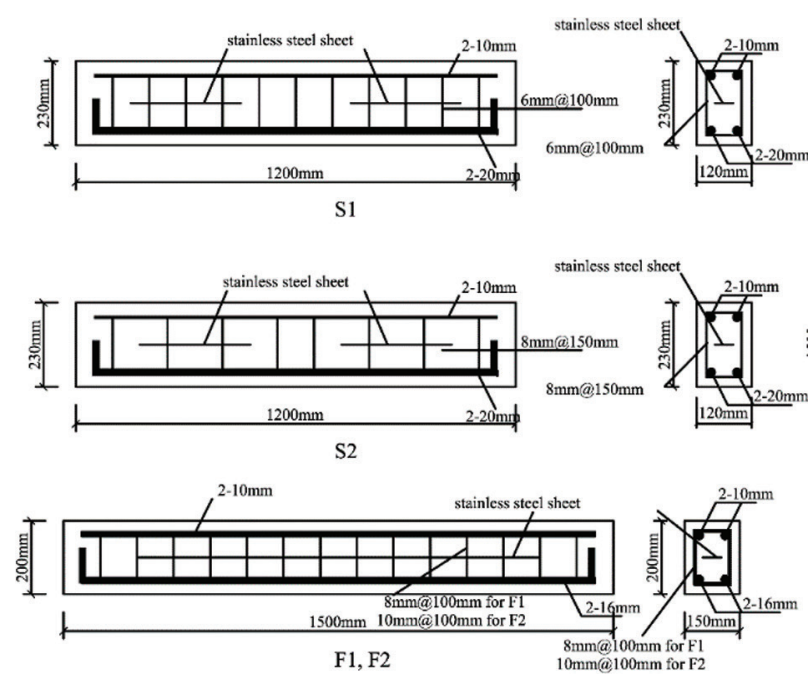

Figure 1. Details of the tested specimens. 
All specimens were casted from two batches of concrete, wet cured for a period of 7 days and then permitted to dry cure for a period of at least 28 days to achieve the required design strength. After curing, an accelerated corrosion process was applied.

\subsection{Accelerated corrosion}

Figure 2 shows a schematic representation of the test setup for the acceleration corrosion. Sponge that soaks up $5 \% \mathrm{NaCl}$ solution was used to keep concrete in the targeted area wet. Afterward, a piece of stainless steel net was kept close to the sponge. Finally, the outside of the beam was wrapped with a plastic sheet to keep the moisture in the sponge. The corrosion procedure can be divided into two phases, namely the electromigration phase and the wettingdrying-current cycle phase.

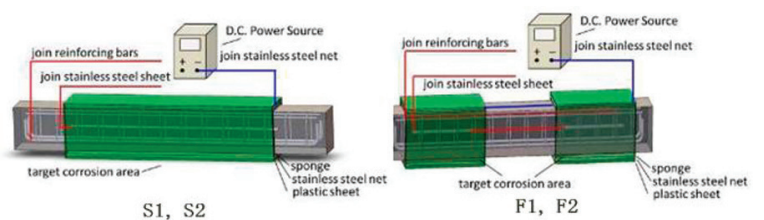

Figure 2. Schematic representation of accelerated corrosion test setup.

In the electromigration phase, chlorides were electromigrated into concrete cover by means of using an electrochemical method. To simulate the realistic chloride ingress in concrete, $2 \mathrm{~mol} / \mathrm{L}$ $\mathrm{NaCl}$ solution was first put in the sponge to make the concrete moisture more than $24 \mathrm{~h}$. Then, the direction of the current flow was adjusted so that the outside stainless steel net became the cathode and the embedded stainless steel sheet served as the anode. Finally, a constant voltage of $30 \mathrm{~V}$ was applied between the outside stainless steel net and the embedded stainless steel sheet using a DC power source. The electromigration time used in the acceleration corrosion tests was determined by the following equation (Tang, 1996):

$$
t_{1}=\frac{R T}{z F E D_{n s s m}}\left[x_{d}-2 \sqrt{\frac{R T x_{d}}{z F E}} \operatorname{erf}^{-1}\left(1-\frac{2 c_{d}}{c_{0}}\right)\right]
$$

where $t_{1}$ is the electromigration time, $R=8.314$ $\mathrm{J} /(\mathrm{mol} \cdot \mathrm{K})$ is the molar gas constant, $T$ is the average absolute temperature of the concrete beams, $z=1$ is the charge number of chloride ions, $F=96480$ $\mathrm{J} /(\mathrm{V} \cdot \mathrm{mol})$ is the Faraday constant, $E$ is the applied electric field strength, $D_{\text {nssm }}$ is the nonsteady state diffusion coefficient, $x_{d}$ is the clear concrete cover thickness, cd is the threshold concentration value of the initial corrosion, and $c_{0}$ is the concentration of free chlorides in the solution. The nonsteady state diffusion coefficient was determined by separate rapid chloride migration tests of concrete cylinders with a diameter of $100 \mathrm{~mm}$ and a thickness of $50 \mathrm{~mm}$. For the present type I and type II concrete, the nonsteady state diffusion coefficients were found to be about $6.67 \times 10^{-12} \mathrm{~m}^{2} / \mathrm{s}$ and $4.00 \times 10^{-12} \mathrm{~m}^{2} / \mathrm{s}$, respectively. By taking $E=300 \mathrm{~V} / \mathrm{m}$, $T=298 \mathrm{~K}, x_{\mathrm{d}}=0.03 \mathrm{~m}, c_{d}=0.4225 \mathrm{~mol} / \mathrm{L}$, and $c_{0}=$ $2 \mathrm{~mol} / \mathrm{L}$, we have the electromigration times of 4.19 and 6.98 days for the type I and type II concretes, respectively.

Previous experience showed that cracks evolve more rapidly in a dry environment than in a humid environment when an accelerated corrosion process is applied. This is probably due to the transport enhancement of the corrosion products away from the steel-concrete interface in the wet concrete. While in the dry concrete, most of the corrosion products stay at the steel-concrete interface. As a consequence of this, pore pressure may increase and extra tensile stresses at the interface may also be generated. This leads to the development of concrete cracks and the propagation of cracks through the concrete cover. Hence, to simulate the actual environmental degradation process, a wetting-drying-current cycle was used after the electromigration process. The wetting-drying-current cycle involves 3 days dry followed by 4 days wet. The dry process was achieved by taking off the plastic sheet to dry the sponge, whereas in the wet cycle, the plastic sheet was reapplied to cover over the beam and 5\% $\mathrm{NaCl}$ solution was put in the sponge to make the concrete moisture. For the purpose of an accelerated corrosion, a current density of $2 \mathrm{~A} / \mathrm{m}^{2}$ was applied through the reinforcing steel (acting as the anode) and the stainless steel net (acting as the cathode) using a constant DC current power source. The total galvanizing time was determined using the following formula:

$$
t_{2}=\frac{\gamma_{s} Z_{F e} F \Delta d_{s}}{M_{F e} i}
$$

where $t_{2}$ is the total galvanizing time, $\gamma_{\mathrm{s}}$ is the density of the steel, $Z_{\mathrm{Fe}}$ is the valence of the $\mathrm{Fe}, \Delta d_{\mathrm{s}}$ is the target corrosion depth, $M_{\mathrm{Fe}}$ is the atomic weight of the $\mathrm{Fe}$, and $I$ is the current density. The target corrosion level and the galvanizing time calculated for each tested beam are given in Table 2 .

\subsection{Corrosion-induced cracking}

The distribution of corrosion-induced cracks was copied on a paper by putting a piece of soft glass with a grid of $50 \mathrm{~mm} \times 50 \mathrm{~mm}$ on the specimen surface. The maximum crack width in each grid was recorded. Crack width was measured using a crack visualizer with an accuracy of $0.02 \mathrm{~mm}$ at each grid (see Figure 3). 
Table 2. Summary of experimental responses.

\begin{tabular}{|c|c|c|c|c|c|c|c|c|}
\hline S.D & Concrete & Specimen & $t_{2}$ (days) & $C(\mathrm{~mm})$ & $D(\mathrm{~mm})$ & $\eta_{\text {average }}$ & $\begin{array}{c}w_{c, \text { average }} \\
(\mathrm{mm})\end{array}$ & $\begin{array}{l}w_{c, \max } \\
(\mathrm{mm})\end{array}$ \\
\hline I-6-1 & 1 & $\mathrm{~S} 1$ & 23.93 & 24 & 6 & $10.68 \%$ & 0.06 & 0.08 \\
\hline I-6-2 & I & S1 & 49.23 & 24 & 6 & $27.01 \%$ & 0.08 & 0.12 \\
\hline I-6-3 & I & S1 & 76.16 & 24 & 6 & $37.13 \%$ & 0.12 & 0.20 \\
\hline I-6-4 & I & S1 & 105.10 & 24 & 6 & $42.54 \%$ & 0.12 & 0.40 \\
\hline I-6-5 & I & $\mathrm{S} 1$ & 136.57 & 24 & 6 & $54.15 \%$ & 0.19 & 0.48 \\
\hline I-6-6 & I & S1 & 23.93 & 24 & 6 & $12.94 \%$ & 0.04 & 0.04 \\
\hline I-6-7 & I & $\mathrm{S} 1$ & 49.23 & 24 & 6 & $21.75 \%$ & 0.10 & 0.12 \\
\hline I-6-8 & I & S1 & 76.16 & 24 & 6 & $29.23 \%$ & 0.14 & 0.40 \\
\hline I-6-9 & I & S1 & 105.10 & 24 & 6 & $41.48 \%$ & 0.13 & 0.40 \\
\hline I-6-10 & 1 & s1 & 136.57 & 24 & 6 & $51.42 \%$ & 0.18 & 0.44 \\
\hline I-8-1 & I & $\mathrm{S} 2$ & 31.48 & 22 & 8 & $6.53 \%$ & 0.08 & 0.08 \\
\hline I-8-2 & I & $\mathrm{S} 2$ & 64.76 & 22 & 8 & $11.73 \%$ & 0.13 & 0.24 \\
\hline I-8-3 & I & $\mathrm{S} 2$ & 100.19 & 22 & 8 & $19.54 \%$ & 0.14 & 0.24 \\
\hline I-8-4 & I & $\mathrm{S} 2$ & 138.26 & 22 & 8 & $25.74 \%$ & 0.16 & 0.36 \\
\hline I-8-5 & I & $\mathrm{S} 2$ & 179.66 & 22 & 8 & $32.38 \%$ & 0.19 & 0.68 \\
\hline I-16-1 & I & $\mathrm{F} 1$ & 25.09 & 30 & 16 & $3.25 \%$ & 0.32 & 0.68 \\
\hline |-16-2 & 1 & $\mathrm{~F} 1$ & 31.44 & 30 & 16 & $4.50 \%$ & 1.11 & 1.88 \\
\hline I-16-3 & I & $\mathrm{F} 1$ & 37.83 & 30 & 16 & $5.19 \%$ & 0.79 & 1.48 \\
\hline I-16-4 & 1 & $\mathrm{~F} 1$ & 44.25 & 30 & 16 & $6.97 \%$ & 1.18 & 1.92 \\
\hline I-16-5 & I & $\mathrm{F} 1$ & 50.71 & 30 & 16 & $7.39 \%$ & 1.06 & 2.92 \\
\hline I-16-6 & I & $\mathrm{F} 1$ & 57.20 & 30 & 16 & $8.37 \%$ & 1.01 & 1.88 \\
\hline I-16-7 & I & $\mathrm{F} 1$ & 63.72 & 30 & 16 & $9.91 \%$ & 0.90 & 1.76 \\
\hline I-16-8 & I & $\mathrm{F} 1$ & 71.27 & 30 & 16 & $10.08 \%$ & 1.46 & 3.13 \\
\hline I-16-9 & 1 & $\mathrm{~F} 1$ & 77.96 & 30 & 16 & $11.55 \%$ & 2.38 & 4.48 \\
\hline II-16-1 & II & $\mathrm{F} 2$ & 25.09 & 30 & 16 & $2.91 \%$ & 0.39 & 0.80 \\
\hline II-16-2 & II & $\mathrm{F} 2$ & 31.44 & 30 & 16 & $3.28 \%$ & 1.34 & 2.76 \\
\hline II-16-3 & II & $\mathrm{F} 2$ & 37.83 & 30 & 16 & $4.06 \%$ & 1.54 & 3.51 \\
\hline II-16-4 & II & $\mathrm{F} 2$ & 44.25 & 30 & 16 & $5.14 \%$ & 0.78 & 1.60 \\
\hline II-16-5 & II & $\mathrm{F} 2$ & 50.71 & 30 & 16 & $6.60 \%$ & 0.98 & 2.28 \\
\hline II-16-6 & II & $\mathrm{F} 2$ & 57.20 & 30 & 16 & $7.16 \%$ & 1.72 & 3.40 \\
\hline II-16-7 & II & $\mathrm{F} 2$ & 63.72 & 30 & 16 & $8.65 \%$ & 1.55 & 4.16 \\
\hline II-16-8 & II & $\mathrm{F} 2$ & 69.29 & 30 & 16 & $9.03 \%$ & 1.66 & 3.45 \\
\hline II-16-9 & II & $\mathrm{F} 2$ & 75.80 & 30 & 16 & $10.21 \%$ & 1.42 & 2.39 \\
\hline
\end{tabular}
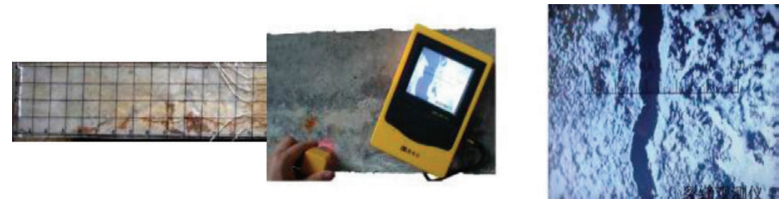

Figure 3. Measurement of corrosion-induced cracks on concrete surface. (a) Measurement grid on the specimen surface and (b) Crack width measurement.

\subsection{Corrosion level and rust evaluation}

After it had corroded, loading bearing test was carried out for each specimen, which has been discussed in authors' other articles (Xia et al., 2011, 2012) and will not be the focus in this article. After the failure of specimen, the corroded reinforcing steel bars were taken out from the specimen and cut into specimens for further tensile tests (Xia et al., 2013). For the identification phase of deposits, $\mathrm{X}$-ray diffraction and thermal analysis were also performed to characterize corrosion products (Zhao, Ren, Dai, \& Jin, 2011). The bars were then cleaned and measured according to the method mentioned in ASTM G1-03 (ASTM, 2003), from which the average cross-section loss ratios $\eta$ average were calculated using the weight 
ratios between the corroded and uncorroded bars (see Table 2).

\section{RESULT AND DISCUSSION}

\subsection{Corrosion pattern and rush composition}

Figure 4 gives typical corrosion patterns of the reinforcing steel bars corroded in concrete. It is clear that the corrosion of the steel bar not only reduced its cross-section irregularly but also altered the rib shape on a ribbed bar surface. The steel bar presented a more serious corrosion on the surface facing to the concrete cover than the surface away from the concrete cover, which is much alike what happen in long-term field corrosion in concrete (Trejo, Pillai, Hueste, Reinschmidt, \& Gardoni, 2009; Yuan \& Ji, 2009). It is noticed from the figures that the corrosion of the steel bar was pitted with somewhat abrupt changes in bar geometry and much variation in the cross-sectional area and is much like the corrosion pattern-induced by chloride aggression.

X-ray diffraction and thermal analysis results for characteristics of corrosion products were presented in Zhao et al. (2011), which showed that, by the above corrosion methodology, both the composition and the expansion rate of the corrosion rust were much alike the corrosion rust from the steel bar corroded in a natural chloride aggressive environment. Especially, the expansion coefficient shows to be 3.14 for the above test and 3.02 for a sample rebar, which was corroded in RC port, Yokosuka, Japan, for 40 years. The similar expansion coefficient of the wettingdrying-current test to a natural explosion can develop a similar corrosion-induced crack propagation process to the in situ RC structures in chloride aggressive environment.

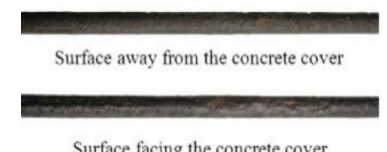

(a)

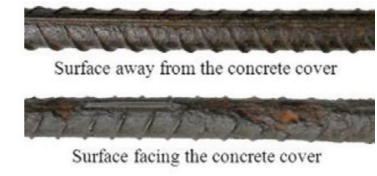

(b)
Figure 4. Corrosion patterns for reinforcing steel bars corroded in concrete. (a) Plain bars and (b) ribbed bars.

\subsection{Determination of the pit concentration factor}

Rodriguez, Ortega, Casal, and Diez (1996b) gives the relation between pit attack and reinforcement diameter loss:

$$
d=d_{0}-\alpha x
$$

where $d$ is the residual rebar diameter; $d_{0}$ is the initial rebar diameter; $x$ is the pit penetration; and $\alpha$ is the pit concentration factor.
The rebar cross-sectional area of the pit corroded steel bar can be evaluated by the following analogy equation (Xia et al., 2013):

$$
A_{s}=\left(1-2.1 \eta_{\text {average }}\right) A_{s 0}
$$

where $A_{\mathrm{s}}$ is the residual rebar area; $A_{\mathrm{s} 0}$ is the initial rebar area; $x$ is the pit penetration; and $\eta_{\text {average }}$ is the average cross sectional loss of the corroded rebar.

We then can obtain the relation between pit concentration factor and average cross-sectional loss of the corroded rebar:

$$
\alpha=\frac{2\left(1-\sqrt{1-2.1 \eta_{\text {average }}}\right)}{1-\sqrt{1-\eta_{\text {average }}}}
$$

Then we can deduce the value of pit concentration factor by Eq. (5). Figure 5 gives the relationship between pit concentration factor and average crosssectional loss in the range of $0-50 \%$. It shows the pit concentration factor in this experiment is between 4.2 and 6.0, which is in accordance with the conclusion of Gonzalez, Andrade, Alonso, and Feliu (1995), $4<\alpha<8$.

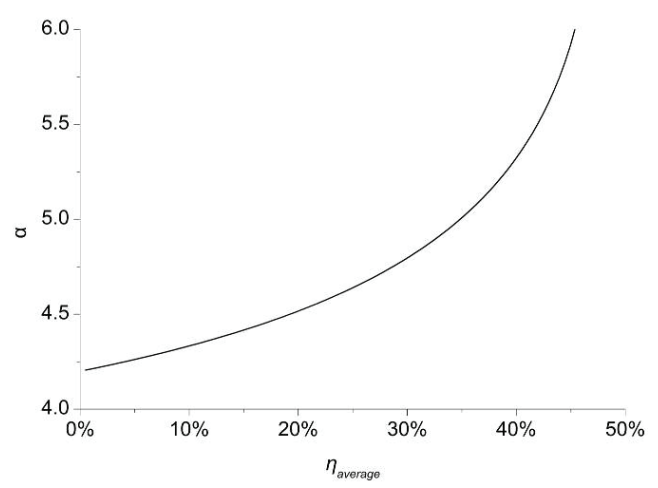

Figure 5. The relationship between pit concentration factor and average cross-sectional loss of the corroded rebar.

\subsection{Steel rebar cross-section loss initiating cracking}

We choose the model proposed by Vidal et al. (2004) to predict the steel rebar cross-section loss initiating cracking:

$$
\eta_{c r}=1-\left[1-\frac{\alpha}{d_{0}}\left(7.53+9.32 \frac{c}{d_{0}}\right) \times 10^{-3}\right]^{2}
$$

where $c$ is the concrete cover depth. It should be noticed that this model does not take the concrete characteristics into account. Thus, further study is needed as we only used two types of concrete with different mixtures. According to the experimental result, the rebar cross-section loss-inducing concrete cracking is below $10 \%$ for all specimen in the current study; thereby the pit concentration factora can be taken as 4.3. 


\subsection{Corrosion-induced crack analysis}

For one location of the specimen, the sum of crack widths on the two beam surfaces, due to the same corroded area of one bar, was calculated. Figure 6 shows an example of two crack configurations, in which the configuration one has an equivalent width wc, eq corresponding to the sum of the width of two cracks, while the configuration two has an equivalent width wc, eq corresponding to the width of only one crack (Vidal et al., 2004).

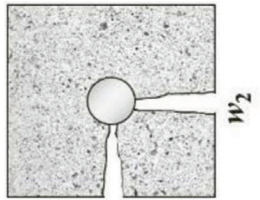

$w_{1}$

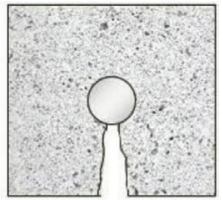

$w_{3}$
Figure 6. Two equivalent crack configurations for the same corrosion state.

Using the method shown in Figure 3, surface crack maps in the tested specimen were obtained and are plotted. Crack distribution and crack width (in millimeters) at each grid of the corrosion zone are drawn on the maps. According to the above assumption, the average crack width $w_{c, \text { average }}$ and maximum crack width $w_{c, \text { max }}$ for each tested specimen were also calculated, and the corresponding results are given in Table 2 .
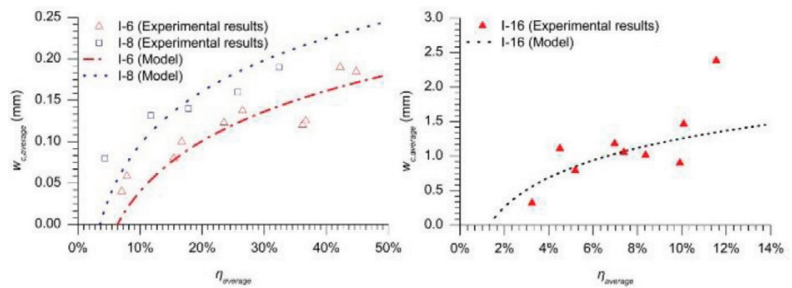

Figure 7. The relationships between the corrosion induced average crack width and average cross-section loss ratio.

Figure 7 shows the relationship between the average cross-section loss ratio and the average crack widths. It can be seen that the average crack widths increase with the average cross-section loss ratio, which is similar to what was found previously (Alonso et al., 1998; Malumbela et al., 2011; Mullard \& Stewart, 2011; Val, Chernin, \& Stewart, 2009; Vidal et al., 2004; Zhang, 2010). However, these previous studies (Alonso et al., 1998; Mullard \& Stewart, 2011; Vidal et al., 2004; Zhang, 2010) with regard to corrosioninduced crack widths have linear relationship with the corrosion ratio. On the contrary, Vu and Stewart (2005) proposed a nonlinear crack propagation relationship. However, as can be seen in Figure 6, the crack widths increase with corrosion rate as expected; at the time that concrete cracks, there is an abrupt increase in crack width, which reflects the assumed quasi-brittle nature of concrete. This phenomenon is consistent with the analytical model proposed by Li et al. (2006) and Zheng, Zhou, and Xu (2006); unfortunately, no experimental data were available to verify these models in their articles. After cracking, the crack width's increasing rate slows down as the corrosion develops. This can be explained as the corrosion products penetrating into the concrete pores and cracks, and, moreover, it is expected that the corrosion products amount should depend on the crack propagation. The cracks are being filled gradually over time, and the thicker the concrete cover the longer it will take to fully fill a crack (Val et al., 2009). By multivariate regression analysis, we can obtain the corrosion-induced average crack width as:

$$
w_{c, \text { average }}=K \ln \frac{\eta_{\text {average }}}{\eta_{c r}}
$$

where $K$ is a parameter that should depend on the concrete cover, rebar diameter, concrete porosity and, subsequently, on the water-cement ratio, and the concrete compressive strength. In this article, experimental result from two types of concrete cannot quantitatively but qualitatively draw conclusion considering the influence of concrete mixture. Further research, and especially experimental research, is needed.

Besides, the cover depth has double effects on the corrosion-induced crack width and should be considered serious for different situations. Generally, the initial corrosion ratio inducing cracking increases proportionately with the cover depth, but inversely with the rebar diameter. In another words, with the same corrosion ratio, the smaller the rebar diameter or the larger the cover depth, the smaller the corrosioninduced crack width. However, in another aspect, the measurement of the crack width was conducted on the surface of the concrete, so the larger cover depth will induce a larger corrosion-induced crack width (Wei, Zhou, Zhang, \& Li, 2008).

Therefore, in this article, we only consider the influence of cover/diameter ratio to determine parameter $K$. According to the result of above multivariate regression analysis, $K$ for average crack width can be given as the following expression:

$$
K=\left(\frac{c}{d}\right)^{-12} \times 10^{3}+0.087
$$

In comparison with the proposed model, most of the experimental values are close to the modeling natural logarithm curves, except the point of I-16 with average cross-section loss of $11.55 \%$. This significant distinction may be produced by experimental error and can be 
excluded from the tested data. As mentioned above, this model does not take the concrete characteristics, such as concrete porosity, and compressive strength, into account. Thus, the experimental data available do not allow any quantitative conclusion. However, by comparing the test data from I-16 and II-16, it can be seen in Figure 8 that, generally, the corrosion-induced crack of II-16 is opening wider than those of I-16 for the same corrosion level. This may due to the concrete of II-16 has a lower water to cement ratio than I-16. Therefore, the concrete of II-16 has a relative smaller porosity than $\mathrm{I}-16$, then fewer corrosion products can penetrate into concrete pores, and the same amount of corrosion products can produce a wider crack width. From another aspect, the concrete of II-16 has a higher compressive strength than $\mathrm{I}-16$, so the concrete of II-16 is more brittle than I-16, which will also help to produce a wider crack width.

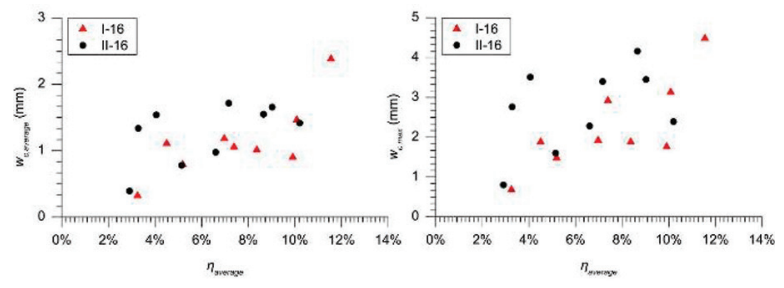

Figure 8. The influence of concrete type on crack propagation.

Figure 9 shows the relationship between the maximum crack width and the average crack width. The figure shows that the maximum crack width increases with the average crack width, and the relationship between them can be approximately represented by a linear line with a slope of 2.1. It seems that this relation have no correlation with the specimen type. Note that the average crack width in real structures is very difficult to obtain; this can conveniently afford us a simple visual inspection method to estimate the average crack width by just measuring the maximum crack width on the surface of in situ RC structures. For a field structure, maximum crack widths can be measured with reasonable accuracy with no difficulty.

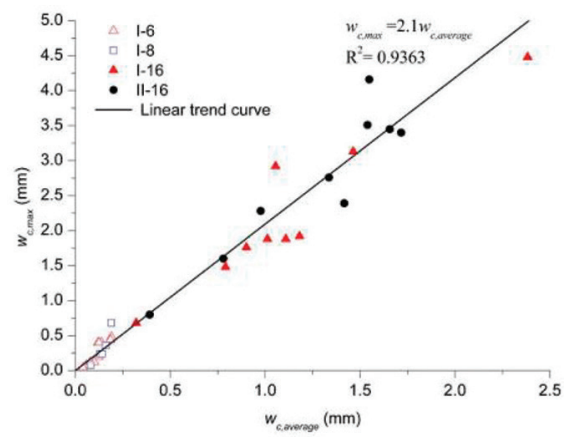

Figure 9. The relationship between the average width and maximum width of the corrosion-induced cracks.
Figure 10 shows the relationship between the average cross-section loss ratio and the maximum crack widths. Although the data are somewhat scatter, the figure does show that the maximum crack widths also increase with the average cross-section loss ratio. According to the result of above multivariate regression analysis, $K$ for maximum crack width can be given as the following expression:

$$
K=2\left(\frac{c}{d}\right)^{-12} \times 10^{3}+0.22
$$
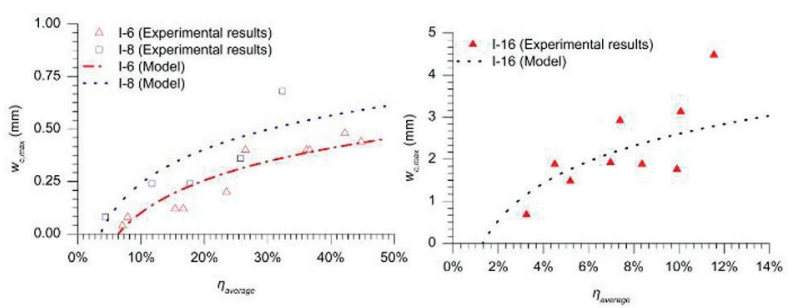

Figure 10. The relationships between the corrosion-induced maximum crack width and average cross-section loss ratio.

\section{PREDICTION OF CORROSION LEVEL OF CORRODED REBAR IN RC STRUCTURES}

An attempt has been made to use the experimental data in proposing a predictive model for the estimation of the corrosion level of a corroded rebar that are subjected to reinforcement corrosion. Note that the crack widths are affected by not only the rebar diameter and concrete cover thickness but also the concrete characteristics. Therefore, the formulae derived here may need to be verified with more experimental data to take the concrete properties in to account. Whether or not they can also be applied to other concrete requires a further study. Nevertheless, it is conceivable that using the crack width to evaluate the corrosion damage amount of embedded rebar in concrete is much easy and convenient.

The proposed crack width prediction model can be used to find out the corrosion level of RC structure that has suffered corrosion damage. As an example, to evaluate the corrosion level of an on-site concrete structure damaged by the reinforcing steel corrosion, the maximum crack width could be first measured and used to find the corrosion level for a pre-evaluation. If a further validation is needed, grid net could be drawn on the target member to obtain an average crack width. Based on the obtained crack widths, one can calculate the corrosion-induced damage of corroded rebar.

\section{CONCLUSIONS}

This work attempted to obtain information contributing to the development of an empirical formula to predict 
the crack width of RC structures due to the corrosion of reinforcing steel. Based on the experimental results obtained with this investigation, the following conclusions can be drawn:

- Both the average crack widths increase with the average cross-section loss ratio. At the time that concrete cracks, there is an abrupt increase in crack width, which reflects the assumed quasibrittle nature of concrete. After cracking, the crack width's increasing rate slows down as the corrosion develops.

- The maximum crack width seems to have a linear relationship with the average crack width. Therefore, the maximum crack width can be used to provide a prediction of corrosion damage of corroded rebar in a corrosion environment.

- The proposed crack width prediction model can be used to find out the corrosion level of $R C$ structure that has suffered corrosion damage. Besides using the average corrosion-induced crack width to evaluate the corrosion damage of corroded rebar in a corrosion environment, the maximum corrosion-induced crack width can also be a feasible and easy-get choice. However, the influence of the concrete characteristics on the crack width should be considered.

\section{ACKNOWLEDGMENTS}

This work was supported by the Fundamental Research Funds for the Central Universities (2014FZA4020), the Natural Science Foundation of China $(51278459,51378456,51178417)$ and the European Union Research Council via a research grant (FP7-PEOPLE-2011-IRSES-294955).

\section{REFERENCES:}

Aligizaki, K. K. (1999). Modeling of concrete cracking due to corrosion of embedded reinforcement. Pennsylvania: The Pennsylvania State University.

Allamt, I. M., Maslehuddin, M., Sariciment, H., \& Al Mana, A. (1994). Influence of atmospheric corrosion on the mechanical properties of reinforcing steel. Construction and Building Materials, 8(1), 35-41.

Alonso, C., Andrade, C., Rodriguez, J., \& Diez, J. M. (1998). Factors controlling cracking of concrete affected by reinforcement corrosion. Materials and Structures, 31(211), 435-441.

Andrade, C., Alonso, C., \& Molina, F. J. (1993). Cover cracking as a function of bar corrosion: Part 1 experimental test. Materials and Structures, 26(162), 453-464.

ASTM. (2003). Standard practice for preparing, cleaning, and evaluating corrosion test specimens.
Standard G1-03. West Conshohocken, PA: Author.

Gonzalez, J. A., Andrade, C., Alonso, C., \& Feliu, S. (1995). Comparison of rates of general corrosion and maximum pitting penetration on concrete embedded steel reinforcement. Cement and Concrete Research, 25(2), 257-264.

Li, C. Q., Melchers, R. E., \& Zheng, J. J. (2006). Analytical model for corrosion-induced crack width in reinforced concrete structures. ACI Structural Journal, 103(4), 479-487.

Malumbela, G., Moyo, P., \& Alexander, M. (2011). Influence of corrosion crack patterns on the rate of crack widening of RC beams. Construction and Building Materials, 25(5), 2540-2553.

Monteiro, P. J., Morrison, F., \& Frangos, W. (1998). Non-destructive measurement of corrosion state of reinforcing steel in concrete. ACl Materials Journal, 95(6), 704-709.

Mullard, J. A., \& Stewart, M. G. (2011). Corrosioninduced cover cracking: New test data and predictive models. ACl Structural Journal, 108(1), 71-79.

Richardson, M. G. (2002). Fundamentals of durable reinforced concrete. London: Taylor \& Francis.

Rodriguez, J., Ortega, L. M., Casal, J., and Diez, J. M. (1996a). Assessing structural conditions of concrete structures with corroded reinforcement. Proceedings of the 4th International Congress on concrete in the service of mankind, Dundee UK: Spon Press, 65-78.

Rodriguez, J., Ortega, L. M., Casal, J., \& Diez, J. M. (1996b). Corrosion of reinforcement and service life of concrete structures. Durability of Building Materials and Components, 7(1), 117-126.

Song, H., \& Saraswathy, V. (2007). Corrosion monitoring of reinforced concrete structures-A. International Journal of Electrochemical Science, 2, 1-28.

Stewart, M. G. (2010). Reliability safety assessment of corroding reinforced concrete structures based on visual inspection information. ACI Structural Journal, 107(6), 671.

Suo, Q., \& Stewart, M. G. (2009). Corrosion cracking prediction updating of deteriorating $\mathrm{RC}$ structures using inspection information. Reliability Engineering and System Safety, 94(8), 1340-1348.

Tang, L. (1996). Electrically accelerated methods for determining chloride diffusivity in concrete - current development. Magazine of Concrete Research, 48(176), 173-179.

Trejo, D., Pillai, R. G., Hueste, M., Reinschmidt, K. F., \& Gardoni, P. (2009). Parameters influencing corrosion and tension capacity of post-tensioning strands. ACl Materials Journal, 106(2), 144-153. 
Val, D. V., Chernin, L., \& Stewart, M. G. (2009). Experimental and numerical investigation of corrosion-induced cover cracking in reinforced concrete structures. Journal of Structural Engineering, 135, 376.

Vidal, T., Castel, A., \& Francois, R. (2004). Analyzing crack width to predict corrosion in reinforced concrete. Cement and Concrete Research, 34(1), 165-174.

Vu, K., \& Stewart, M. G. (2005). Predicting the likelihood and extent of reinforced concrete corrosion-induced cracking. Journal of Structural Engineering, 131, 1681.

Vu, K., Stewart, M. G., \& Mullard, J. (2005). Corrosion-induced cracking: Experimental data and predictive models. ACl Structural Journal, 102(5), 719-726.

Wei, J., Zhou, X. W., Zhang, K. Q., \& Li, P. (2008). Correlation analysis of durability and concrete cover thickness of concrete structure. International Journal of Structural Engineering, 1(2), 207-214.

Williamson, S. J., \& Clark, L. A. (2000). Pressure required to cause cover cracking of concrete due to reinforcement corrosion. Magazine of Concrete Research, 52(6), 455-467.

Xia, J., Jin, W. L., \& Li, L. Y. (2011). Shear performance of reinforced concrete beams with corroded stirrups in chloride environment. Corrosion Science, 53(5), 1794-1805.
Xia, J., Jin, W. L., \& Li, L. Y. (2012). Effect of chlorideinduced reinforcing steel corrosion on the flexural strength of reinforced concrete beams. Magazine of Concrete Research, 64(6), 471-485.

Xia, J., Jin, W. L., Zhao, Y. X., \& Li, L. Y. (2013). Mechanical performance of corroded steel bars in concrete. Proceedings of the Institution of Civil Engineers: Structures and Buildings, 166(5), 235-246.

Yuan, Y. S., \& Ji, Y. S. (2009). Modeling corroded section configuration of steel bar in concrete structure. Construction and Building Materials, 23(6), 2461-2466.

Zhang, R., Castel, A., \& François, R. (2010). Concrete cover cracking with reinforcement corrosion of RC beam during chloride-induced corrosion process. Cement and Concrete Research, 40(3), 415-425.

Zhang, R. (2010). Concrete cover cracking with reinforcement corrosion of RC beam during chloride-induced corrosion process. Cement and Concrete Research, 40(3), 415-425.

Zhao, Y. X., Ren, H. Y., Dai, H., \& Jin, W. L. (2011). Composition and expansion coefficient of rust based on X-ray diffraction and thermal analysis. Corrosion Science, 53(5), 1646-1658.

Zheng, J. J., Zhou, X. Z., \& Xu, S. L. (2006). Prediction of crack width of chloride contaminated reinforced concrete structures. Zurich-Uetikon, Switzerland: Trans Tech Publications Ltd, pp. 610-617. 